\title{
Northeastern Ontario Forest Ecosystem Classification as a tool for managing marten habitat
}

\author{
by J.C. Bowman ${ }^{1,3}$, J.-F. Robitaille ${ }^{1}$ and W.R. Watt ${ }^{2}$
}

In northeastern Ontario, the Forest Ecosystem Classification (NE-FEC) system has been used in a Habitat Suitability Matrix (NE-HSM) for forest wildlife. This paper examines whether American martens (Martes americana) responded significantly to different NE-FEC Site Types, and compares this response with suitability values in the NE-HSM. Use of Site Types by martens deviated significantly from availability; Site Type 5 (black spruce) was preferred and Site Type 7 (hardwood) was avoided. In general, the NE-HSM was consistent with field results; but it was concluded that some adjustments should be made to the suitability values for martens in the Northeastern Ontario Forest Habitat Suitability Matrix.

Key words: Forest ecosystem classification, habitat suitability matrix, marten, Martes americana

\section{Introduction}

The development of a Forest Ecosystem Classification (FEC) system is one coarse-filter (Noss 1987) approach to Integrated Resource Management (Douglas 1988). These classifications are becoming common in Ontario (Jones et al. 1983; Merchant et al. 1989; Sims et al. 1989; McCarthy et al. 1994). FEC types are derived from field surveys at the forest stand level. Vegetation and soil types are determined and the stand is classified as a particular ecosystem type that allows for future identification and planning. Classification occurs under a management-oriented soil and vegetation aggregate. Different aggregates (e.g. "Operational Group", "Treatment Unit" and "Site Type"), which are based on similar measures, have been developed in different management regions of Ontario (Sims and Uhlig 1992).

FEC systems may be used to manage habitat for wildlife (MacInnes and Voigt 1986). In northeastern Ontario, the FEC system (NE-FEC) was used to develop a regional Habitat Suitability Matrix (NE-HSM) (D'Eon and Watt 1994). The Site Type aggregate of the NE-FEC system was chosen as the basis for the matrix that includes all amphibians, reptiles, birds and mammals common to the area. The suitability of different Site Types for each animal species was determined from the literature. Three levels of suitability ("avoided", "used" and "preferred") were recognized for each of five successional stages: forest initiation, regeneration, young, mature, and old growth. The

\footnotetext{
'Department of Biology, Laurentian University, Sudbury, Ontario, Canada P3E 2C6.

${ }^{2}$ Northeast Science and Technology, Ontario Ministry of Natural Resources, Timmins, Ontario, Canada P4N IS7.

${ }^{3}$ Current Address: New Brunswick Cooperative Fish and Wildlife Research Unit, University of New Brunswick, P.O. Box 44555, Fredericton, New Brunswick, Canada E3B 6C2.
}

Dans le nord-est de l'Ontario, le système de classification des écosystèmes forestiers (NE-CEF) a été utilisé dans une Matrice de Qualité de l'Habitat (NE-MQH) pour la faune forestière. Nous avons examiné si la martre d'Amérique (Martes americana) répondait de manière significative aux différents Types de Site et comparé cette réponse aux valeurs du NEMQH. L'utilisation des Types de Site par la martre était significativement différente de leur disponibilité; le Type de Site 5 (épinette noire) a été préféré et le Type de Site 7 (Bois francs) a été évité. En général, le NE-MQH était cohérent avec nos résultats de terrain, cependant, nous concluons que quelques changements devraient être apportés aux valeurs de qualité pour la martre dans la Matrice de Qualité de l'Habitat de la ForIet du Nord-Est Ontarien.

Mots clés: Classification des Écosystèmes forestiers, Matrice de Qualité de l'Habitat, martre, Martes americana

NE-HSM allows habitat management for many animal species simultaneously, depending on their response to different Site Types - a coarse-filter approach.

One habitat specialist that may benefit from coarse-filter management is the American marten (Martes americana), a medium-sized member of the weasel family (Mustelidae) that is common in boreal forests of North America. Several authors have indicated that martens prefer mature and overmature coniferous forests (Marshall 1951; Koehler and Hornocker 1977; Soutiere 1979; Thompson and Colgan 1994). Old forests have high canopy closure and large amounts of coarse woody debris, believed to offer martens protection from avian predators as well as resting, denning and foraging opportunities (Thompson and Harestad 1994). Intensive logging across the marten's range has resulted in local extirpations of the species in many parts of North America (Gibilisco 1994). As timberdriven forest management is being replaced with more integrated approaches, tools like the NE-HSM are proposed as a basis for managing wildlife habitat.

In this study, field data was evaluated to determine whether the NE-FEC system has potential as a descriptor of marten habitat. Our findings were compared to those suggested in the Northeastern Ontario Forest Habitat Suitability Matrix (D'Eon and Watt 1994).

\section{Study Area}

The $1100-\mathrm{km}^{2}$ study area was south of Timmins, Ontario $\left(48^{\circ} 30^{\circ} \mathrm{N} 81^{\circ} 40^{\prime} \mathrm{W}\right)$ in the Northern Clay Belt forest region (Rowe 1972). The topography was nearly level and drainage in the area was poor.

The northeastern Ontario region has a history of clearcut logging and mid- to late-successional forests dominated the study area $(75 \%$ of the area was stands between 50 and 89 years 
old). Black spruce (Picea mariana) was the most common overstory species. Balsam fir (Abies balsamea) was abundant and often associated with trembling aspen (Populus tremuloides) and white birch (Betula papyrifera). Eastern white cedar (Thuja occidentalis) and less frequently, tamarack (Larix laricina), occurred in swampy lowlands. Stands of jack pine (Pinus banksiana) were common in drier, sandy sections. White spruce (Picea glauca) were scattered in the few upland sections. The understory was characterized by thick patches of speckled alder (Alnus rugosa) in wet lowlands and riparian areas. Other species, such as mountain maple (Acer spicatum), leatherleaf (Chamaedaphne calyculata), creeping snowberry (Gaultheria hispidula), and beaked hazel (Corylus cornuta) occurred throughout the area. Common herb layer species included Sphagnum spp., Clintonia borealis, Trientalis borealis, Streptopus roseus, and Aralia nudicaulis. Descriptions of the different NE-FEC Site Types are provided by D'Eon and Watt (1994) and McCarthy et al. (1994).

Although registered traplines existed in the study area, we attempted to minimize potential impacts that harvesting the marten population could have. Before transects were established, we ensured that no traplines would be active for martens during the study period. Further, transects were not established within $1 \mathrm{~km}$ of registered traplines. We cannot ensure that removal of martens during the fall trapping period did not affect our study, and in this sense, the marten population was an exploited one. The area was subject to Part 3a of the Ontario fur management regulations (Anonymous 1993).

\section{Methods}

Line transects (1 to $3 \mathrm{~km}$ in length) were designated on Forest Resource Inventory (FRI) maps. During February and March 1994, transects were walked and all snow tracks of wildlife were recorded. Intersections of marten tracks and transects were considered to indicate marten habitat use; these intersections and all $100-\mathrm{m}$ intervals were marked with flagging tape. We completed $142 \mathrm{~km}$ of snow tracking on 57 transects.

Winter weather was favourable for snow tracking. Mean daily temperature ranged from -28.5 to $-1.6^{\circ} \mathrm{C}$ in February, and from -15.9 to $0.2^{\circ} \mathrm{C}$ in March. It was assumed that severe cold had a negligible impact on marten activity as only 2 of 57 transects were sampled following temperatures below $-20^{\circ} \mathrm{C}$ (Thompson 1994). There were 23 days of snowfall ranging from a trace to $8.2 \mathrm{~cm}$ in February. Snow tracking was completed on $18 \mathrm{March}$ and up to that point, there were 17 days of snowfall in the month, ranging from a trace to $5.8 \mathrm{~cm}$. Snow depth gradually decreased from 61 to $29 \mathrm{~cm}$ (Environment Canada, unpubl. data). Tracks were recorded on 12 -h to one-day-old snow cover during $86 \%$ of the study period. Between May and October 1994, 100-m segments along 33 of the snow-tracked transects were sampled for FEC Site Type. Segments without marten tracks were sampled at the midpoint $(50 \mathrm{~m})$, whereas segments with marten intercepts were sampled at the intercept closest to the midpoint only. The $100-\mathrm{m}$ segments were sampled only once. At each sampling point, a dichotomous flowchart was used to classify a $10 \times 10 \mathrm{~m}$ quadrat into one of 22 alphanumeric NE-FEC Site Types, based on one soil sample collected with an auger and herb, shrub, and tree diversity characteristics (McCarthy et al. 1994).

A subsample of 25 transects ( $N=565$ quadrats) was randomly selected for analysis; the remaining subset of data
Table 1. Relative occurrence of 22 northeastern Ontario Forest Ecosystem Classification Site Types (McCarthy et al. 1994) from 565 sampled quadrats near Timmins, Ontario. - indicates absence in the field samples

\begin{tabular}{llcc}
\hline $\begin{array}{l}\text { Site } \\
\text { type }\end{array}$ & Description & $\begin{array}{c}\text { No. of } \\
\text { quadrats }\end{array}$ & $\begin{array}{c}\text { \%of } \\
\text { quadrats }\end{array}$ \\
\hline 1 & Very shallow soil & 21 & 3.7 \\
2a & Jack pine-coarse soil & 47 & 8.3 \\
2b & Jack pine-very coarse soil & 3 & 0.5 \\
3a & Mixedwood-medium soil & 1 & 0.2 \\
3b & Mixedwood-coarse soil & 67 & 11.9 \\
4 & Jack pine-black spruce-coarse soil & 32 & 5.7 \\
5a & Black spruce-fine soil & 18 & 3.2 \\
5b & Black spruce-medium soil & 7 & 1.2 \\
6a & Mixedwood-fine soil & 9 & 1.6 \\
6b & Conifer mixedwood-medium soil & - & - \\
6c & Hardwood mixedwood-coarse soil & 79 & 14.0 \\
$7 \mathrm{a}$ & Hardwood-fine soil & 28 & 5.0 \\
$7 \mathrm{~b}$ & Hardwood-medium soil & 8 & 1.4 \\
8 & Black spruce-feathermoss-sphagnum & 17 & 3.0 \\
9 & Conifer-moist soil & 52 & 9.2 \\
10 & Hardwood-moist soil & 23 & 4.1 \\
11 & Black spruce-labrador tea & 21 & 3.7 \\
12 & Black spruce-speckled alder & 22 & 3.9 \\
13 & Conifer-speckled alder & 96 & 17.0 \\
14 & Black spruce-leatherleaf & 14 & 2.5 \\
15 & Tolerant hardwood mixedwood & - & - \\
16 & Sugar maple-yellow birch & - & - \\
\hline
\end{tabular}

was used in another ongoing study. Chi-square analysis was conducted to determine whether martens used NE-FEC Site Types in proportion to their availability at two levels of FEC resolution: (1) a higher resolution composed of alphanumeric subdivisions (e.g. ST 2a, ST 2b called alphabetical in D'Eon and Watt (1994) as found in the FEC flowchart, and (2) a lower resolution with numeric subdivision (e.g. ST 2), obtained by collapsing alphanumeric subdivisions, hence matching resolution found in the NE-HSM (Table 1). Significant $(P<0.05)$ chi-square relationships were analyzed using the a posteriori Bonferroni procedure to determine simultaneous confidence intervals (Byers et al. 1984) with alpha level at 0.10. This significance level was chosen a priori because of the rigor involved in conducting the Bonferroni procedure with a large number of Site Types. Preference indices (use/availability) were developed at each level of habitat resolution. In the NEHSM, suitability of Site Types is available for five successional stages. The mature seral stage was selected for comparison because it most closely approximated this study area. The three NE-HSM suitability levels were converted into numeric values: avoided habitat $=-1.0$, used habitat $=0.0$, and preferred habitat $=+1.0$. These values were compared with field-based preference indices using Kendall's rank correlation only at the lowest level of resolution, because alphanumeric subdivisions were not available in the NE-HSM.

Soil type, also associated with the NE-FEC system, was analyzed for marten use with chi-square goodness-of-fit tests. The Bonferroni procedure was used for a posteriori analysis.

\section{Results}

Nineteen of a possible 22 NE-FEC Site Types were present on the study area. SiteType 13 (mixed conifer-speckled alder) was most abundant. Also prevalent were ST $6 \mathrm{c}$ (hardwood mixedwood-coarse soil) and ST 3b (mixedwood-coarse soil) (Table 1). Martens did not use Site Types in proportion to their 

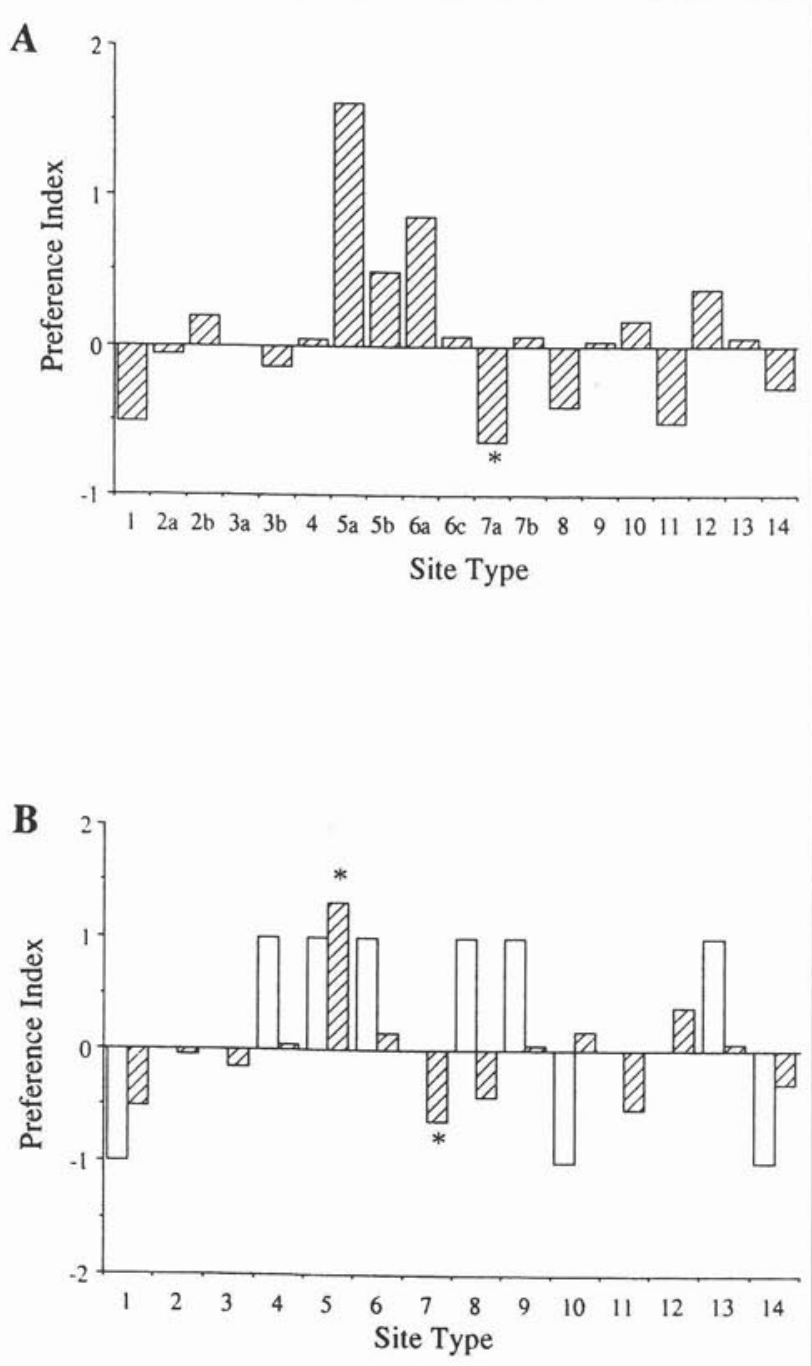

Fig. 1. Field-based and Habitat Suitability Matrix (NE-HSM)derived preference indices of martens for northeastern Ontario Forest Ecosystem Classification (NE-FEC) Site Types, at two levels: (A) higher resolution, with alphanumeric subdivisions (no NEHSM values available) and (B) lower resolution, with numeric subdivisions. See D'Eon and Watt (1994) and McCarthy et al. (1994) for reviews of the NE-HSM and NE-FEC systems, respectively. *indicates a value outside of simultaneous confidence interval at alpha $=$ 0.10 .

availability $\left(X^{2}=38.94 ; \mathrm{df}=18 ; P<0.01\right.$; Cramer's $\left.V=0.26\right)$. The Bonferroni procedure demonstrated that ST 7a (hardwoodfine soil) was used significantly less than expected (Fig. 1A). At the lower resolution level, 14 types were found present on the study area. Martens did not use combined Site Types as expected on the basis of availability $\left(X^{2}=33.42 ; \mathrm{df}=13 ; P\right.$ $<0.001$; Cramer's $V=0.24$ ). A posteriori analysis of confidence intervals indicated that ST 5 (black spruce) was used significantly more than expected while ST 7 (hardwood) was used significantly less than expected. Preference indices for these Site Types were positively correlated with suitability values found in the NE-HSM (Tau $=0.36 ; \mathrm{n}=14 ; P<0.05)$ (Fig. 1B).

All six soil types represented in the NE-FEC system were present in the study area (Table 2). Marten use of soil types
Table 2. Relative occurrence of six northeastern Ontario Forest

Ecosystem Classification (McCarthy et al. 1994) soil types from 565 quadrats sampled near Timmins, Ontario

\begin{tabular}{lcc}
\hline Soil type & No. of quadrats & \% of quadrats \\
\hline Very shallow & 21 & 3.7 \\
Organic & 153 & 27.1 \\
Moist mineral & 92 & 16.3 \\
Sandy to coarse loamy & 228 & 40.4 \\
Medium loamy to silty & 16 & 2.8 \\
Fine loamy to clayey & 55 & 9.7 \\
\hline
\end{tabular}

did not deviate significantly from expected $\left(X^{2}=5.45 ; \mathrm{df}=\right.$ 5; $P=0.36$; Cramer's $V=0.10$ ).

\section{Discussion}

The NE-FEC system was a useful descriptor of marten habitat relationships in this study area. In general, preferred Site Types were black spruce dominated, while hardwoods were avoided. These findings are consistent with other research on marten habitat (Buskirk and Powell 1994). These findings support the assumption of D'Eon and Watt (1994) that the low resolution numeric subdivisions provides an adequate system for classifying marten habitat and that examination at high resolutions is unnecessary.

There was a general agreement (significant correlation) between these findings and the NE-HSM. The suitability matrix is literature-based and needs field validation. Our field observations and the model were consistent with three exceptions. Site Type 7 (hardwood) was significantly avoided by martens. This contrasts with the NE-HSM values, where ST 7 is classified as "used" by martens. Several authors have suggested that hardwood stands do not provide adequate overhead cover for martens in winter, or adequate resting, denning, and foraging sites, and hence are avoided (Marshall 1951; Koehler and Hornocker 1977; Soutiere 1979; Thompson and Colgan 1994). Site Type 4 (jack pine-black spruce-coarse soil) was not preferred by martens. This is contrary to the NE-HSM. Although conifer-dominated stands are believed to be preferred by marten, xeric-site conifers in particular, are not (Buskirk and Powell 1994). Xeric-site species such as jack pine produce less coarse woody debris (CWD) than do mesic-site species and CWD is considered an important habitat element for martens (Corn and Raphael 1992). The finding that Site Type 8 (black spruce-feathermoss-sphagnum) was not preferred by martens is also contrary to the NE-HSM. Although the high proportions of black spruce in this Site Type suggest high suitability for marten, other habitat requisites such as canopy closure and amount of CWD were lacking on ST 8 sites (Bowman 1996).

Although the NE-FEC system was not invalidated as a descriptor of habitat suitability for martens, we believe inconsistencies warrant some limitations to its application. In particular, ecosystem type classifications do not account for some habitat characteristics, such as woody debris, stand age and height, canopy closure, and tree diameter, that influence marten habitat selection (Buskirk and Powell 1994; Thompson and Harestad 1994). These habitat characteristics are included in the NE-FEC system indirectly through associations with the Site Types. Direct measurement of these variables, as in Habitat Suitability Index models, may be a more effective method 
of assessing habitat suitability for marten. While preparing an HSI model for the region (Bowman 1996), we found that downed logs, stand height, and canopy closure significantly affected marten habitat selection.

The NE-FEC system offers a cost-effective means of using coarse resolution information about wildlife species and incorporating this information into forest management. The pre-defined nature of the NE-FEC system enhances its potential for computer-based management approaches (e.g. decision support systems) (Thompson and Weetman 1995). As field validation continues, some refinement of the NE-HSM may be necessary. Based on our study, three changes are suggested: ST 7 should be classified as "poor", rather than "used", marten habitat; and both ST 4 and ST 8 should be "used", rather than "preferred".

\section{Acknowledgements}

The authors acknowledge financial support from Northeast Science and Technology, Ontario Ministry of Natural Resources, and logistic aid from the Timmins District office of OMNR. Technical assistance was provided by enthusiastic field crews. We appreciate comments on an earlier version of this manuscript by J.-P. Ouellet, and two anonymous reviewers.

\section{References}

Anonymous. 1993. Summary of the fur management regulations. Ont. Min. Nat. Resour., Toronto, ON.

Bowman, J.C. 1996. Two approaches to modeling marten (Martes americana) habitat suitability in northeastern Ontario. M.Sc. Thesis, Laurentian University, Sudbury, ON. 100 p.

Buskirk, S.W. and R.A. Powell. 1994. Habitat ecology of fishers and martens. Pp. 283-296 In Martens, sables and fishers: biology and conservation. S.W. Buskirk, A.S. Harestad, M. G. Raphael, and R.A. Powell, Eds. Cornell University Press, Ithaca, NY.

Byers, C.R., R.K. Steinhorst and P.R. Krausman. 1984. Clarification of a technique for analysis of utilization-availability data. J. Wildl. Manage. 48: 1050-1053.

Corn, J.G. and M.G. Raphael. 1992. Habitat characteristics at marten subnivean access sites. J. Wildl. Manage. 56: 442-448.

D'Eon, R.G. and W.R. Watt. 1994. A forest habitat suitability matrix for northeastern Ontario. Ont. Min. Nat. Resour., Northeast Science and Technology, Timmins, TM004. $83 \mathrm{p}$.

Douglas, L.A. 1988. The development and evolution of the integrated resource management philosophy within the Ministry of Natural Resources. For. Chron. 64: 267-269.
Gibilisco, C.J. 1994. Distributional dynamics of modern Martes in North America. Pp. 59-71 In: Martens, sables, and fishers: biology and conservation. S.W. Buskirk, A.S. Harestad, M.G. Raphael and R. A. Powell, Eds. Cornell University Press, Ithaca, NY.

Jones, R.K., G. Pierpoint, G.M. Wickware, J.K. Jeglum, R.W. Arnup and J.M. Bowles. 1983. Field guide to forest ecosystem classification for the Clay Belt, Site Region 3E. Ont. Min. Nat. Resour., Toronto, ON. 123 p.

Koehler, G.M. and M.G. Hornocker. 1977. Fire effects on marten habitat in the Selway-Bitterroot wilderness. J. Wildl. Manage. 41: 500-505.

MacInnes, C.D. and D.R. Voigt. 1986. Wildlife reaction to forest sites. Pp. 121-131 In: Site classification in relation to forest management. COJFRC Symposium Proceedings, O-P-14.

Marshall, W.H. 1951. Pine marten as a forest product. J. For. 49: 899-905.

McCarthy, T.G., R.W. Arnup, J. Nieppola, B.G. Merchant, K. Taylor and W.J. Parton. 1994. Field guide to forest ecosystems of northeastern Ontario. Ont. Min. Nat. Resour., Northeast Science and Technology. FG001.

Merchant, B.G., R.D. Baldwin, E.P. Taylor, B.A. Chambers, A.M. Gordon, and R.K. Jones. 1989. Field guide to a productivity oriented pine forest ecosystem classification for the Algonquin Region 5E, first approximation. Ont. Min. Nat. Resour., Toronto, ON. 131 p.

Noss, R.F. 1987. From plant communities to landscapes in conservative inventories: a look at the Nature Conservancy (USA). Biol. Conserv. 41: 11-37.

Rowe, J.S. 1972. Forest regions of Canada. Canadian Forestry Service, Department of the Environment, Ottawa, ON. 165 p.

Sims, R.A. and P. Uhlig. 1992. The current status of forest site classification in Ontario. For. Chron. 68: 64-77.

Sims, R.A., W.D. Towill, K.A. Baldwin and G.M. Wickware. 1989. Field guide to forest ecosystem classification for northwestern Ontario. Ont. Min. Nat. Resour., Toronto, ON. 191 p.

Soutiere, E.C. 1979. Effects of timber harvesting on marten in Maine. J. Wildl. Manage. 43: 850-860.

Thompson, I.D. 1994. Marten populations in uncut and logged boreal forests in Ontario. J. Wildl. Manage. 58: 272-280.

Thompson, I.D and P.W. Colgan. 1994. Marten activity in uncut and logged boreal forests in Ontario. J. Wildl. Manage. 58: 280-288. Thompson, I.D. and A.S. Harestad. 1994. Effects of logging on American martens. Pp. 355-367 In: Martens, sables, and fishers: biology and conservation. S.W. Buskirk, A.S. Harestad, M.G. Raphael and R.A. Powell, Eds. Cornell University Press, Ithaca, NY.

Thompson, W.A. and G.F. Weetman. 1995. Decision support systems for silviculture planning in Canada. For. Chron. 71: 291-298. 